\title{
Implementasi Manajemen Berbasis Sekolah (MBS) pada Kelas Awal di Kota Gorontalo
}

\author{
Isnanto $^{\varpi_{1}}$, Yustika ${ }^{2}$ \\ Pendidikan Guru Sekolah Dasar, Universitas Negeri Gorontalo \\ DOI: $\underline{10.31004 / \text { obsesi.v4i2.514 }}$
}

\begin{abstract}
Abstrak
Penelitian ini bertujuan untuk mengetahui lebih jauh mengenai pemahaman warga sekolah tentang Manajemen Berbasis Sekolah (MBS), dinamika implementasi MBS, karakteristik MBS dan tindak lanjut program MBS untuk anak usia 6-8 Tahun. Jenis penelitian kualitatif dengan pendekatan studi kasus. Pengumpulan data menggunakan wawancara, observasi, dan dokumentasi. Hasil penelitian yaitu MIT Al-Ishlah sudah memahami konsep MBS dari adanya keterbukaan dan kemampuan sekolah dalam merumuskan program-program sekolah yaitu program puncak tema belajar konstekstual, program madrasah guru, program gerakan untuk orang tua, program gemayur. Sekolah melakukan tindak lanjut dimulai dari evaluasi program yang memberatkan anak, ketertiban anak, efektivitas pembelajaran, dan program lainnya yang tidak berjalan dengan baik.
\end{abstract}

Kata Kunci: manajemen berbasis sekolah; manajemen pendidikan; anak usia dini.

\begin{abstract}
This study aims to find out more about the understanding of school residents about School Based Management (SBM), the dynamics of SBM implementation, SBM characteristics and the follow-up of the SBM program for children aged 6-8 years. This study uses the qualitative research with a case study approach. Data collection uses interviews, observation, and documentation. The results showed that MIT Al-Ishlah, have understood the concept of SBM from the openness and ability of schools to formulate school programs is the peak program of contextual learning themes, madrasa teacher programs, movement programs for parents, gemayur programs. Schools follow up starting with program evaluations that are burdensome for children, orderliness of children, effectiveness of learning, and other programs that are not going well.
\end{abstract}

Keywords: school-based management; education management; early childhood.

Copyright (c) 2020 Isnanto, Yustika

$\triangle$ Corresponding author:

Email Address : hilliaizza@gmail.com (Jambi, Indonesia)

Received 11 April 2020, Accepted 14 April 2020, Published 15 April 2020 


\section{PENDAHULUAN}

Beberapa ide atau pemikiran baru tentang manajemen pendidikan dalam menemukan model sekolah yang efektif salah satunya adalah manajemen berbasis sekolah. Vally \& Daud (2015) karakter sekolah yang manajemennya efektif berfokus pada empat yaitu dimensi lingkungan, program restrukturasi, kepemimpinan strategis dan sekolah iklim. Dari hal tersebut manajemen berbasis sekolah (MBS) merupakan ide baru dan populer dari proses desentralisasi dibidang pendidikan diseluruh dunia. Manajemen berbasis sekolah terinspirasi dari model pendidikan Amerika Serikat, kemudian beberapa Negaranegara mengimplementasikan manajemen berbasis sekolah yang sangat efektif meningkatkan sekolah seperti Inggris, Berita, Australia, New land, Spayol, Canada, Brazil, El Salvador, Hong Kong, China, Uganda, Thailand, Argentina, Mexico, Qatar, Kenya, Iran, Senegal, serta Indonesia (Bako Umar et al., 2017; Lee \& Chiu, 2017; Moradi et al., 2016; Ng \& Chan, 2008).

Menajemen berbasis sekolah menjadi semakin popular dikalangan pendidikan dan pembuat kebijakan, ketika otonomi dan fleksibelitas sekolah meningkat, sekolah dapat menciptakan serta mengimplementasikan program-program yang bermanfaat bagi kebutuhan anak (Kwan \& Li, 2015). Bentuk idealnya manajemen berbasis sekolah mengacu pada pemberdayaan kepala sekolah dengan otonomi atas control fisikal, kurikulum, dan pengembangan professional (Grinshtain \& Gibton, 2018). Manajemen berbasis sekolah melibatkan anggota sekolah, orang tua dan masyarakat (Arar \& Abu-Romi, 2016; Bako Umar et al., 2017). Partisipasi antara anggota sekolah, orang tua dan masyarakat sangat penting dalam meningkatkan kualitas pendidikan yang ada di dunia (Nir, 2013). Dengan adanya pastisipasi tersebut, maka akan tercapainya tujuan pembelajaran dan meningkatkan efektivitas pendidikan di sekolah berbagai Negara.

Selain itu, manajemen berbasis sekolah berpengaruh pada peran dan akuntabilitas kepala sekolah serta guru dalam meningkatkan manajemen dan administrasi sekolah lebih baik dari pada cara tradisional (Muslihah, 2015). Cheng (1993) menjelaskan bahwa manajemen berbasisi sekolah berarti sekolah yang tugas manajemennya diatur sesuai dengan karakteristik dan kebutuhan sekolah itu sendiri yang terdiri dari dewan direksi, pengawas, kepala sekolah, guru, orang tua, dan anak yang memiliki banyak otonomi dan tanggung jawab yang lebih besar untuk penggunaan sumber daya untuk memecahkan masalah dan melaksanakan secara efektif kegiatan mengajar serta pengembangan jangka panjang. Sebaliknya, manajemen sekolah tradisional seringkali ditandai oleh kontrol ketat eksternal dari kantor pusat sekolah yang tugas manajemen dilakukan di bawah instruksi otoritas pusat eksternal, sering tidak sesuai dengan karakteristik dan kebutuhan sekolah.

Menurut Mulyasa (2017) Implementasi manajemen berbasis sekolah terdiri dari: 1) Manajemen kurikulum dan program pembelajaran, 2) Manajemen pendidik, 3) Manajemen anak, 4) Manajemen keuangan, 5) Manajemen fasilitas pendidikan, dan 6) Hubungan manajemen sekolah dengan masyarakat dan layanan khusus manajemen. Sedangkan Laurens Kaluge \& Lilik Kustiani (2017) terdapat tujuh komponan dalam manajemen berbasis sekolah yaitu 1) membentuk dan memberdayakan komite sikolah, 2) perencanaan pengembangan sekolah, 3) rencana pengembangan sekolah dan kegiatan sekolah, 4) adanya interaksi antara sekolah dan masyarakat, 5) anggaran sekolah dikeknbangkan oleh tim untuk memastikan bahwa sekolah dapat mengimplemnetasikan rencana kegiatan program, 6) evaluasi diterapkan dalam program, 7) pelaporan kegiatan dari sekolah individu ke berbagai pihak siterapkan secara transparan.

Di Indonesia pengelolaan pendidikan anak usia dini, pendidikan dasar, dan pendidikan menengah dilaksanakan berdasarkan standar pelayanan minimal dengan prinsip MBS. Yang artinya bahwa pendidikan anak usia dini menggunakan pendekatan manajeman berbasis sekolah (Sjamsir et al., 2017). Tata kelola PAUD dijelaskan dalam lampiran Peraturan Menteri Pendidikan Nasional Nomor 58 Tahun 2009 tentang Standar Pendidikan Anak Usia Dini yaitu Prinsip pengelolaan, bentuk layanan, perencanaan 
pengelolaan, pelaksanaan pengelolaan, dan pengawasan dan evaluasi. Sehingga PAUD menerapkan manajemen berbasis sekolah yang ditunjukkan dengan kemandirian, kemitraan, partisipasi, keterbukaan dan akuntabilitas.

Pada dasarnya setiap sekolah mempunyai bentuk pengelolaan yang berbeda-beda. Hal tersebut dipengaruhi oleh bagaimana kemampuan sekolah dalam menerapkan MBS. Sekolah harus mengetahui kebutuhan sekolahnya, sumber dayanya dan harus mampu mendayagunakan seluruh potensinya (Roza et al., 2020; Yunita et al., 2020). Secara umum MBS bertujuan untuk memberikan kesempatan kepada sekolah agar sekolah menjadi lebih mandiri atau memberdayakan sekolah melalui kewenangannya (Elmelegy, 2015; Hasbullah, 2006). Penerapan MBS akan berhasil apabila didukung oleh sumber daya yang professional, mempunyai kecukupan dana, tersedianya fasilitas yang memadai serta adanya dukungan yang tinggi dari berbagai pihak terkait baik warga sekolah, orang tua maupun masyarakat (Mulyasa dalam Andang, 2014).

Madrasah Ibtidaiyah Terpadu Al-Ishlah (MIT Al-Ishlah) Kota Gorontalo merupakan salah satu sekolah swasta unggulan yang ada di Provinsi Gorontalo. Berdasarkan hasil wawancara awal dengan Bapak Herlis Setiawan Karim, S.Pd, selaku kepala madrasah di MIT Al-Ishlah Kota Gorontalo pada akhir juli 2018, bahwa tenaga pengajar di MIT Al-Ishlah tidak ada yang berstatus PNS namun, sekolah tersebut bisa menyamai keunggulan dengan sekolah-sekolah lainnya. Sekolah dapat merumuskan program-program inovatif yang disesuaikan dengan kebutuhan sekolah seperti 3G (Gemayur, Gemarikan dan Gemaruah), adanya program madrasah guru sebagai upaya mengupgrade kemampuan guru demi meningkatkan kualitas guru dalam mengelola pembelajaran serta adanya GOM (Gerakan Orang Tua Mengaji) yang dikhususkan untuk orang tua anak. Program-peogram tersebut merupakan program yang sangat jarang atau bahkan belum di terapkan oleh sekolah lainnya.

Beberapa hal di atas tidak terlepas dari adanya kemampuan sekolah dalam menerapkan MBS. Menurut peneliti, dalam merumuskan program-program tersebut sekolah harus memiliki pemahaman mengenai konsep MBS. Dengan adanya pemahaman tentang MBS, sekolah harus bisa menerima segala sesuatu yang dapat membawa perkembangan sekolah dan menepis segala sesuatu yang berdampak buruk bagi sekolah. Dengan demikian, Akan mudah bagi sekolah untuk menyeimbangkan antara input, proses dan output. Ketiga hal tersebut harus saling menopang satu sama lain. Input di perlukan untuk dapat menunjang proses pembelajaran, baik dalam segi tenaga pengajar, sarana dan prasarana, biaya pendidikan, dan harapan-harapan sekolah. Apabila input telah tersedia dengan baik, maka proses akan berjalan dengan baik pula. Melalui proses, pendidikan diselenggarakan dan dikembangkan, baik dalam segi kurikulum, penggunaan strategi pembelajaran, serta hubungan sekolah dan masyarakat.

Dari proses tadi, dihasilkan Output. Baik buruknya proses akan mempengaruhi output. Maka dari itu, diperlukan adanya keseimbangan antara ketiganya. Di samping itu, MBS diharapkan agar dapat ditindak lanjuti sebagai perbaikan program MBS ke depan. Sejalan dengan pendapat Nurhasanah \& Dwiyama (2019) MBS merupakan alternative untuk lembaga pendidikan anak usia dini, karena MBS mampu memberikan konstribusi sangat baik serta memperlihatkan keberhasilan yang sanagat signifikan dalam pengembangan pendidikan khususnya dibidang manajemen sekolah. Berdasarkan hal-hal yang telah diuraikan di atas, maka peneliti ingin mengetahui lebih jauh bagaimana Implementasi Manajemen Berbasis Sekolah di Madrasah Ibtidaiyah Terpadu Al-Ishlah Kota Gorontalo. Penelitian ini bertujuan untuk mengetahui lebih lanjut mengenai pemahalaman warga sekolah tentang MBS, dinamika implementasi MBS, Karateristik MBS, dan Tindak Lanjut Program MBS.

Adapun keterbaruan dari penelitian ini adalah pada penelitian ini peneliti berfokus pada impelementasi manajemen berbasis sekolah di Kota Gorontalo dan berpusat pada anak usia 6-8 tahun, sedangkan penelitian yang terdahulu Ayeni \& Ibukun (2013) melihat 
keterlibatan dan efektivitas komite manajemen berbabsis sekolah di tata sekolah, implementasi kurikulum dan hasil belajar anak di sekolah Nigeria. Kemudian penelitian (Bandur, 2012) memeriksa manajemen berbasis sekolah reformasi kebijakan di Indonesia dengan penekanan pada dampak pengalihan wewenang dan tanggung jawab kepada tingkat sekolah, serta tantangan yang dihadapi oleh anggota dewan sekolah, diikuti oleh perbaikan langkah-langkah untuk meminimalkan masalah.

\section{METODOLOGI}

Pada penelitian ini menggunakan jenis penelitian kualitatif dengan pendekatan studi kasus. Penelitian kualitatif menentut adanya pemahaman secara menadalam mengenai data yang diperoleh, sedangkan pendekatan studi kasus dilakukan secara mendalam mengenai suatu kasus tertentu dengan mengumpulkan data, mengambil makna, dan memperoleh kasus tertentu. Pendekatan studi kasus pada penelitian ini menggali secara lebih dalam mengenai Implementasi Menajemen Berbasis Sekolah (MBS) di MIT Al-Islah Kota Gorontalo pada anak usia 6-8 tahun.

Peran peneliti di dalam lapangan merupakan main actor (aktor utama) yang dapat mengungkap fakta-fakta di lapangan. Teknik pengumpulan data yaitu observasi, wawancara dan dokumentasi. Sumber data yang digunakan penelitian data primer dan sekunder. Analisis data pada penelitian kualitatif ini yaitu, reduksi data, penyajian data, penarikan kesimpulan (Sugiyono, 2017). Berikut ini gambar tahap penelitian yang dilakukan peneliti.

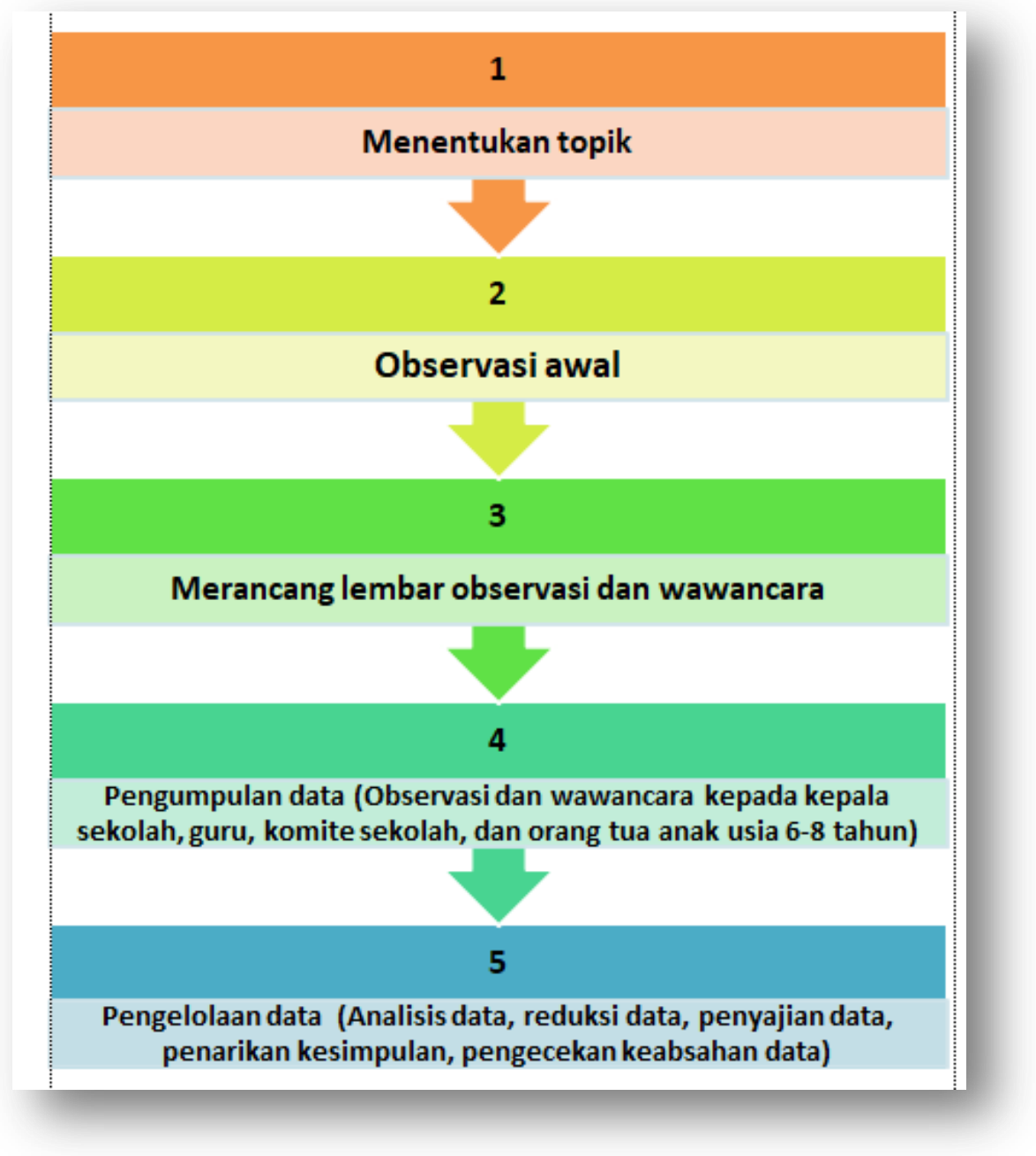

Gambar 1. Tahap-tahap Penelitian 
DOI: $10.31004 /$ obsesi.v4i2.4514

\section{HASIL DAN PEMBAHASAN}

Pemahaman warga sekolah tentang MBS diuraikan dari informasi konsep MBS, Keterbukaan, Kemandirian. Berikut ini penjelasan masing-masing uraian tersebut. Pertama, informasi konsep MBS. Sekolah menyampaikan informasi yang sesuai dengan konsep MBS, dimana sekolah lebih leluasa dalam mengelola sekolah tanpa ada campur tangan dari pemerintah walaupun sedikitnya masih menyesuaikan dengan kebijakan pemerintah.

Tabel 1. Hasil Wawancara Informasi Konsep MBS

\begin{tabular}{lll}
\hline Narasumber & Tanggal dan Waktu & \multicolumn{1}{c}{ Hasil Wawancara } \\
\hline W. RK & "I3-02-2019,11.00 & "Iya kalo misalnya kita itu memang dia \\
& terdesentralisasi untuk yang manajemennya". \\
& "desentralisasi pendidikan yang dari pusat \\
& diserahkan sepenuhnya ke madrasah yah. \\
& Alhamdulillah kalau saat ini dengan kebijakan itu \\
& sekolah leluasa mengelola tanpa ada campur tangan \\
& dari pihak kementrian walaupun beberapa mungkin \\
& e kita mungkin saja yang hanya bersifat ini bagitu" \\
& "Kalau ada kebijakan dari sana terkait dengan ujian \\
W. HSK & nasional, terkait dengan tanggal-tanggal \\
& pelaksanaanya itu yang kita siarkan dengan mereka \\
& tapi sepenuhnya pengelolaan itu kita di tingkat \\
& sekolah"
\end{tabular}

Meninjau dari keterangan tersebut, bahwa dengan adanya desentralisasi pendidikan sekolah diberikan kewenangan dan tanggung jawab sepenuhnya dalam mengelola sekolah tanpa ada campur tangan dari pemerintah meskipun sedikitnya masih perlu penyesuaian dengan kebijakan pemerintah, tetapi selebihnya sekolah diberikan kebebasan dalam mengelola dan didasarkan pada ketentuan yang ada. Dengan demikian sekolah memahami wujud dari desentralisasi pendidikan. Sebagaimana hasil wawancara yang dilakukan guru di MIT Al-Ishlah pada table 2 berikut.

Tabel 2. Hasil Wawancara Informasi Konsep MBS oleh Guru MIT Al-Ishlah

\begin{tabular}{|c|c|c|}
\hline Narasumber & Tanggal dan Waktu & Hasil Wawancara \\
\hline W. GR & $12-02-2019,11.20$ & $\begin{array}{l}\text { "di sekolah Al-Islah e sudah melaksanakan namanya } \\
\text { MBS yaitu menejemen berbasis sekolah. Dimana, } \\
\text { dari segi e pembelajaran itu sudah diatir oleh } \\
\text { kurikulum. Dari mulai guru dan strategi } \\
\text { pembelajarannya itu memang sudah dikelola atau } \\
\text { sudah diatur ole kurikulum sekolah dan segi } \\
\text { keuangan juga" }\end{array}$ \\
\hline W. RK & $13-02-2-19,11.00$ & $\begin{array}{l}\text { "fasilitas jelas kita punya kewenangan mengelola } \\
\text { fasilitas yang ada". }\end{array}$ \\
\hline W. YA & $12-02-2019,09.35$ & $\begin{array}{l}\text { "kegiatan-kegiatan yang ada di sekolah program- } \\
\text { program di sekolah, sekolah yang memutuskan. } \\
\text { "kewenangan misalnya organisir segala seuatu yang } \\
\text { ada di sekolah. Jadi guru, anak semua yang terdapat } \\
\text { dalam lingkungan sekolah termasuk komunikasi } \\
\text { dengan masyarakat" }\end{array}$ \\
\hline
\end{tabular}

Kedua yaitu Keterbukaan. Sekolah menyampaikan program-program sekolah serta penggunaan dana yang sudah digunakan maupun belum digunakan baik lewat grup Whats App maupun rapat pertemuan dengan orang tua anak usia 6-8 tahun. Sebagaimana yang disampaikan salah satu infoman pada table berikut. 
Tabel 3. Hasil Wawancara Keterbukaan MBS

\begin{tabular}{lll}
\hline Narasumber & Tanggal dan Waktu & Hasil Wawancara \\
\hline W. GR & "Sangat sekali terbuka. kalo tidak terbuka pasti ada \\
& banyak respon negatif dari orang tua. Jadi apa-apa \\
& disini semuanya itu pasti terbuka. Misalnya ada e \\
& kegiatan yang tidak terlaksana, maka itu akan \\
& dilaporkan ketika evaluasi semester ganjil. Misalnya, \\
& sudah dievaluasi semester ganjil maka itu \\
& disampaikan ke orang tua bahwa ada beberapa \\
& kegiatan yang tidak terlaksana. Dan jika kegiatan itu \\
& tidak terlaksana maka, anggaran yang kemarin sudah \\
& dikumpulkan yang sempat tidak dipakai itu akan \\
& dimasukan keanggaran yang berikutnya itu di \\
& semester genap. Jadi orang tua tidak mengumpul \\
& seperti yang dianggarkan seperti yang untuk semester \\
& genap. Misalnya ada 1 anggaran yang tidak terpakai \\
& misalnya 20 ribu misalnya setiap anak itu dananya \\
& akan di save tidak dikembalikan tapi di save untuk \\
& semester genap. Jadi jika ada anggaran yang \\
& disemester genap itu membutuhkan dana 20 ribu \\
maka kami tidak lagi memintakan ke orang tua tapi & sudah mengambil dana yang sudah di save tadi". \\
\hline
\end{tabular}

Keterangan di atas dikonfirmasi informan bahwa sekolah terbuka dengan orang tua anak usia 6-8 tahun mengenai pembangunan dan kegiatan, baik secara langsung maupun tidak langsung. Sebagaimana dijelaskan pada table sebagai berikut.

Tabel 4. Hasil Wawancara Keterbukaan MBS

\begin{tabular}{lcl}
\hline Narasumber & Tanggal dan Waktu & \multicolumn{1}{c}{ Hasil Wawancara } \\
\hline W. LA & 18-02-2019,09.48 & "Terbuka bahkan terbuka sekali. Semua program \\
& disampaikan makanya di awal semester itu di \\
& tingkat jenjang disampaikan bahwa semester ini \\
& ada gemayur.. gerakan makan sayur. Gemarikan.. \\
& jadi anak-anak bawa makanannya sayur. Itu \\
& disampaikan untuk semua program yang berlaku \\
& sesekolah itu disampaikan di jenjang” \\
& "Iya ada dikasi tahu itu dari sekolah. Ada \\
W. IU & pembangunan, ada untuk kegiatan, ada yang di \\
& grup WA, ada juga saat-saat bertemu dengan anak \\
& di sekolah".
\end{tabular}

Ketiga yaitu Kemandirian. Hal yang membedakan MIT Al-Ishlah dengan yang lain yaitu sekolah bisa menggalang dana dari masyarakat khususnya orang tua anak di luar dari SPP. Sekolah Negeri akan menganggapnya sebagai pungutan liar tetapi bagi MIT Al-Ishlah itu salah satu bentuk kewajaran selama itu masih disetujui oleh salah orang tua anak usia 6-8 tahun. Sebagaimana yang diungkapkan oleh informan pada table berikut: 


\section{Tabel 5. Hasil Wawancara Kemandirian Sekolah}

\begin{tabular}{lcl}
\hline Narasumber & Tanggal dan Waktu & \multicolumn{1}{c}{ Hasil Wawancara } \\
\hline W. HSK & 14-02-2019, 10.00 & "Alhamdulillah semakin mandiri jadi karena kita juga \\
& swasta kan bisa menggalang bantuan dari orang tua. \\
& Kemandirian juga disitu, kalau di sekolah negeri kan \\
& pungutan sudah tidak bisa. Sudah tidak bisa pungutan \\
& apalagi katanya somo jadi ada pungli dan lain \\
& sebagainya. Kalo kita swasta kemudian di berikan \\
& keluasan yang penting itu tidak memaksa. Kita \\
& sampaikan ke orang tua kita butuh ini, orang tua \\
& sendiri yang sampaikan oh iya saya nanti sampaikan \\
& ini.. saya bantu ini.. ini dan lain sebagainya" \\
\hline
\end{tabular}

Keterangan di atas menunjukan bahwa bahwa label sekolah juga mempengaruhi tingkat kemandirian sekolah. Sekolah tidak hanya mandiri dalam mengelola dana dari orang tua anak usia 6-8 tahun maupun dana BOS, tetapi juga mandiri dalam pengelolaannya. Sebagaimana yang disampaikan informan sebagai berikut: "Semuanya. Kalo untuk yang dikelola secara mandiri berarti semuanya. Meliputi keungannya, pengelolaan kelas, pembelajaran dan semuanya" (W.RK.11.00.13-02-2019).

Dinamika Implementasi MBS terdiri dari Dukungan, Penolakan, Tantangan. Pertama yaitu Dukungan, Sekolah memperoleh dukungan dari masyarakat khususnya orang tua anak usia 6-8 tahun. Salah satu bentuk dukungan orang tua terhadap sekolah yaitu ikut serta dalam program sekolah seperti kegiatan outdoor kelas dan juga bantuan SDM dari orang tua. Dimana, pada kegiatan pengembangan diri, perwakilan orang tua diundang oleh pihak sekolah untuk menjadi guru dan dapat berbagi kepada anak usia 6-8 tahun terkait dengan pekerjaannya. Jika ada yang orang tuanya dokter maka akan menyampaikan materi terkait kesehatan dan yang orang tuanya wirausahawan maka akan menyampaikan materi bagaimana menjadi usahawan kecil. Hal tersebut bukan hanya sebagai suatu pengetahuan bagi anak usia 6-8 tahun tetapi juga bisa menjadi inspirasi bagi anak untuk sukses.

Hal tersebut didukung oleh hasil wawancara dengan informan bahwa dengan berjalannya program MBS, sekolah memperoleh dukungan dari masyarakat khususnya orang tua anak.. "Ada hari dimana salah satu orang tua menjadi volunteer. Volunteer untuk menyampaikan profesinya. Macam kemarin ada kebetulan yang mamanya dokter. Jadi dia menceritakan e materi tentang kesehatan itu di jenjang kelas 3. Mereka itu kadang sekolah hari sabtu, kadang libur. Nah kalo hari sabtu dia sekolah, mereka ada namanya pengembangan diri aa disini mereka noh banyak belajar. Jadi kemarin mereka di ajar tentang mitigasi bencana kalo gempa bumi. Kemudian keselamatan selama berkendara itu ada dokter yang dari orang tua jadi volunteer. Istilahnya volunteer. Kalo ada orang tua yang wiraswasta usahawan dia noh yang bawakan materi tentang bagaimana menjadi usahawan kecil. Itu voulunteer ada kegiatan setelah smesternya 1 kali". (W.LA.09.48. 18-02-2019).

Kedua yaitu Penolakan, selama ini sekolah belum mendapati adanya penolakan khusunya penolakan terhadap program-program sekolah. Hal tersebut menjadi suatu bentuk penghargaan bagi sekolah karena sekolah mampu mengkomunikasikan dan melibatkan orang tua anak. Sebagaimana yang disampaikan oleh salah satu guru di ALIshlah sebagai berikut: "Penolakan selama ini e dari pihak Al-Ishlah belum didapati penolakan-penolakan yang misalnya program yang ada tapi ditolak dari pihak masyarakat tapi malahan didukung. Tidak ditolak". (W.GR.11.20.12-02-2019). Hal tersebut didukung bahwa sekolah menjaga komunikasi dengan orang tua mengenai termasuk menyampaikan program-program kepada orang tua maka orang tua mendukung program sekolah. 
Adapun keterangannya sebagai berikut: "Selama ini tidak ada penolakan sih karena kan programnya istilahnya program yang bagus. Yang itu yang terbaru gemayur, gemar makan buah sama GOM. Itu yang terbaru.". (W.LA.09.48. 18-02-2019). “Tidak ada. Programnya bagus semua". (W.IU.17.18. 18-02-2019).

Ketiga yaitu Tantangan, Dengan adanya perubahan zaman yang semakin menglobal sekolah merasa harus bisa meningkatkan kemampuan para guru agar tidak ketinggalan zaman. Salah satunya mencari artikel tentang generasi milineal dan anak zaman now. "Iya, kalo dari Al-Ishlah itu pasti melihat zaman-zaman yang sudah masuk-masuk ini seperti yang barusan ini kan zaman milineal, anak zaman now aa semua guru itu pasti update informasi bagaimana caranya guru-guru bisa mengimbangi dengan perubahan zaman yang ada. seperti yang kemarin kita itu untuk mengetahui zaman-zaman yang ada maka, diberikan penugasan kepada guru-guru mencari artikel yang berhubungan dengan zaman now, zaman milenial". (W.GR.11.20.12-02-2019). "Jangan sampai anak-anaknya sudah berbuat apa gurunya baru tahu oh iya ternyata dia ini ee sudah masuk ke zaman ini ternyata". (W.GR.11.20.12-02-2019). Hasil wawancara di atas didukung oleh hasil pengamatan dimana, tantangan terbesar yang dihadapi oleh Al-Ishlah yaitu pengaruh zaman karena sekolah tersebut berorientasi pada agama maka dengan adanya pengaruh negatif dari perkembangan zaman tugas terbesar sekolah adalah menanamkan pondasi agama yang kuat terhadap anak-anak dan tetap konsisten dengan apa yang menjadi visi misi Al-Ishlah.

Karakteristik MBS meliputi Output, Proses, dan Input. Berikut ini tabel penjelasan dari hasil penelitian.

Tabel 6. Hasil Penelitian Dari Karakteristik MBS Pada Anak Usia 6-8 Tahun

Karakteristik MBS
Pertama yaitu Output, sekolah berusaha
mencetak prestasi bidang akademik dalam
maupun non akademik. Salah satu prestasi
akademik yang menjadi kebanggaan pihak
sekolah yaitu sekolah dapat meraih medali
perak Bidang Matematika Tingkat Nasional
tahun 2014. Hal tersebut menunjukan bahwa
kualitas MIT Al-Ishlah sudah tidak dapat
diragukan lagi

Kedua yaitu Proses, Dalam menjalankan proses pendidikan di sekolah, terdapat beberapa program sekolah mulai dari proses pembelajaran seperti puncak tema. Dimana, anak usia 6-8 tahun mengunjungi suatu tempat untuk belajar kontektual seperti ke museum, kebun binatang, kebun bunga, dll. Berlangsungnya program sekolah tidak terlepas dari adanya sosok kepala sekolah yang inspiratif dan komunikatif, adanya program madrasah guru untuk meningkatkan kemampuan guru, sekolah berupaya meningkatkan mutu sekolah dan kepala sekolah selalu memberikan support kepada para guru agar mereka selalu nyaman terhadap pekerjaannya, adanya kegiatan GOM yaitu salah satu kegiatan sekolah dengan orang
Hasil Wawancara

Sebagaimana yang disampaikan oleh informan sebagai berikut: "kalo untuk dari akademik sendiri kita juga sudah beberapa kali e menjadi utusan ke tingkat nasional dan alhamdulillah bukan hanya sekedar utusan tapi juga kita pulang membawa medali. Kemudian kalo medali perak, medali perunggu untuk kegiatan-kegiatan olimpiade itu untuk yang akademik. Kemudian, kalo untuk yang non akademik ada juga kegiatan dokcil kemarin kita sampai ke tingkat nasional". (W.RK.11.00.13-02-2019). 


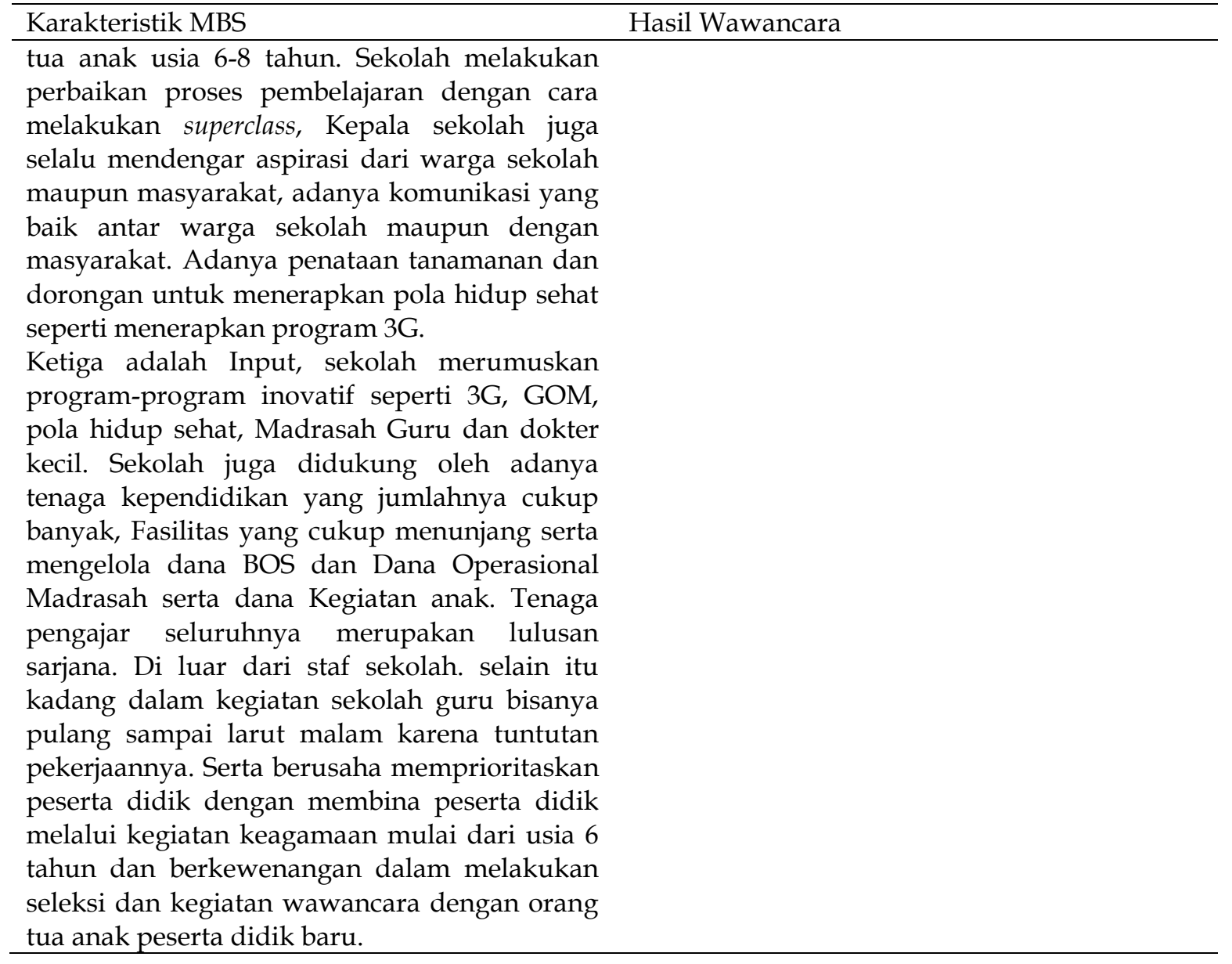

Tindak Lanjut Program MBS. Sekolah melakukan evaluasi mengenai programprogram sekolah pada saat rapat. Evaluasi ada yang dilakukan tiap pekan yaitu hari jum'at, ada yang dilakukan akhir semester dan ada yang dilakukan menjelang akhir tahun atau evaluasi keseluruhan. Dalam melakukan evaluasi sekolah sekolah mengikutserakan orang tua anak usia 6-8 tahun untuk memberikan penilaian berupa angket mengenai pelaksanaan di sekolah baik guru, pelayanan guru maupun tingkat kepuasan orang tua terhadap layanan yang diberikan oleh guru. Dari penilaian tadi akan menjadi bahan evaluasi bagi guru pada saat rapat nanti. Setelah program dievaluasi maka sekolah melakukan perbaikan. Misalnya program yang kurang efektif dapat dikembangkan lagi agar mendapatkan hasil yang efektif. Evaluasi dilakukan pada waktu-waktu tertentu. Sekolah juga biasanya melibatkan orang tua anak usia 6-8 tahun untuk memperoleh masukan-masukan yang akan menjadi bahan evaluasi oleh pihak sekolah pada saat rapat.

Adapun keterangannya sebagai berikut: "Evaluasinya setiap di rapat dan rapat secara umum itu kita saat akhir semester dengan akhir tahun". (W.HSK..10.00.14-02-2019). "Di akhir semester kita akan ada evaluasi orang tua bagimana e tanggapannya terhadap program-program yang sudah kita lakukan. Orang tua anak usia 6-8 tahun mengisi angket. Angket kepuasan orang tua terhadap layanan pendidikan yang kita berikan. Satu tentang guru. Dorang somo ba tulis kari gurunya bagaimana.. e baik ada e sangat baik, baik, kurang baik. Jadi mereka mengisi setelah itu di bawah ada saran-saran perbaikan. Apa yang perlu kita perbaiki oleh pihak madrasah. Semua itu kita akan presentasikan dan itu kita sampaikan ke guru-guru. Ini loh penilaian orang tua terhadap layanan yang antum berikan tentang pelayanan orang tua di grup WhatsApp a kita sampaikan juga ada itu di angket. Ada beberapa poin yang kita tanyakan sampai di penampilan guru. Kita tanyakan ke orang tua bagaimana menurut orang tua penampilan guru pendampingan dia di kelas". (W.HSK..10.00.14-02-2019). Berikut ini diagram konteks Implementasi Manajemen Berbasis Sekolah (MBS). 


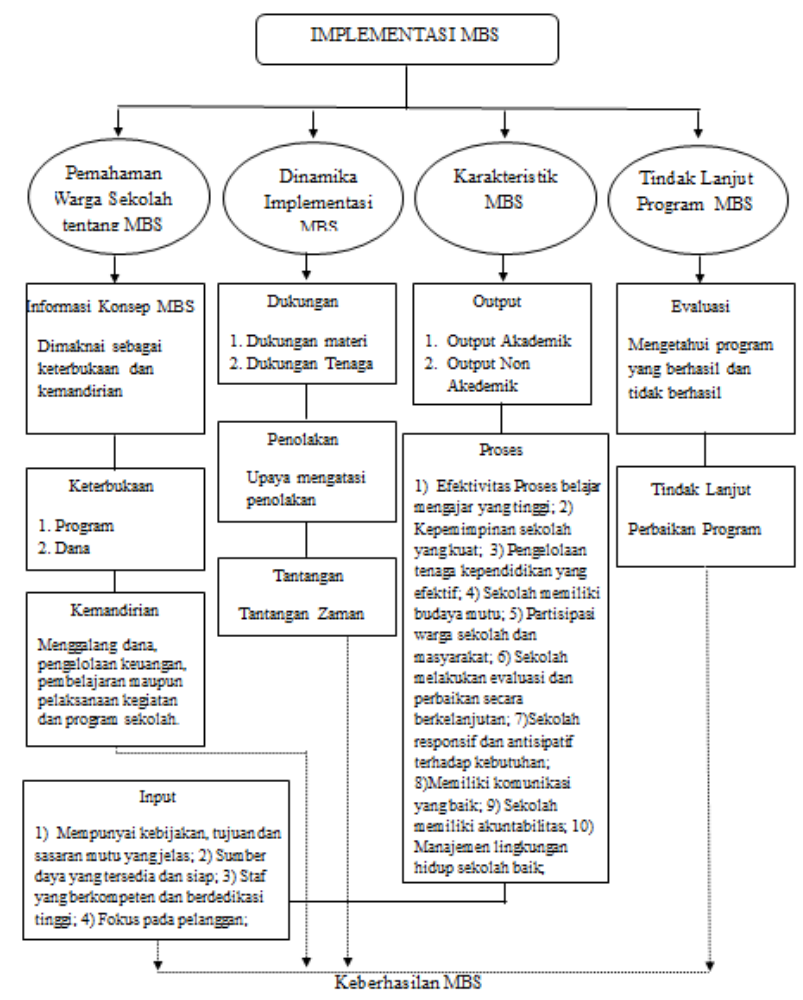

\section{Gambar 2. Diagram Konteks Manajemen Berbasis Sekolah (MBS) di MIT Al-Ishlah}

Mujiburrahman et al., (2018) Menejemen berbasis sekolah pada prinsipnya bertumpu pada masyarakat dan sekolah yang jauh dari birokasi dan sentralistik, MBS berpotensi untuk meningkatkan partisipasi masyarakat, pemerataan, efisiensi, serta manajemen yang bertumpu pada tingkat sekolah. Berdasarkan temuan di atas bahwa pemahaman warga sekolah tentang MBS sudah cukup baik. Dimana sekolah dapat memberikan informasi tentang konsep MBS, sehingga menunjukkan adanya keterbukaan serta kemandirian dalam mengelola sekolah. Penelitian yang dilakukan di sekolah MIT Al-Ishlah melibatkan orang tua dan masyarakat dalam kegiatan sekolah seperti program Gerakan Orang Tua Mengaji. Program-program tersebut didukung oleh orang tua dan masyarakat. Dengan adaya dukungan tersebut membawa kekuatan bersama dalam meningkatkan kualitas sekolah (Zengele, 2015). Sehingga, penerapan yang tepat pada menejemen berbasis sekolah akan memberikan impak yang baik dalam meningkatkan kualitas pendidikan (Bandur, 2012).

\section{SIMPULAN}

Berdasarkan hasil penelitian dan pembahasan menunjukan bahwa implementasi manajemen berbasis sekolah di MIT AL-Ishlah sudah berjalan dengan baik. Hal tersebut dibuktikan dengan adanya pemahaman warga sekolah mengenai MBS dan pengelolaan yang ditawarkan oleh MBS baik proses pembelajaran, fasilitas sekolah, pengambilan keputusan tentang program-program sekolah, mengorganisir segala sesuatu di lingkungan sekolah, guru, anak usia 6-8 tahun serta hubungan sekolah dengan masyarakat serta adanya pelimpahan tanggung jawab dan kewenangan di sekolah. Dengan adanya pengelolaan tersebut sekolah menjadi semakin terbuka dan mandiri. Terbuka mengenai programprogram sekolah dan penggunaan dana serta mandiri dalam menggalang dana dan merumuskan program-program sekolah. 


\section{UCAPAN TERIMAKASIH}

Peneliti ucapkan terima kasih kepada Kepala Sekolah MIT AL-Ishlah Kota Gorontalo, Guru, Komite Sekolah, serta Orang tua anak khususnya usia 6-8 tahun yang terlibat dalam penelitian ini. Tak lupa pula peneliti ucapkan terimakasi pada pihak yang terlibat dalam penelitian ini.

\section{DAFTAR PUSTAKA}

Andang. (2014). Manajemen dan Kepemimpinan Kepala Sekolah (Era Desentralisasi pendidikan) : Konsep, Strategi dan Inovasi Menuju Sekolah Efektif. Ar-Ruzzmedia.

Arar, K., \& Abu-Romi, A. (2016). School-based management: Arab education system in Israel. Journal of Educational Administration, 54(2), 191-208. https:// doi.org/10.1108/JEA-09-2014-0118

Ayeni, A. J., \& Ibukun, W. O. (2013). A Conceptual Model for School-Based Management Operation and Quality Assurance in Nigerian Secondary Schools. Journal of Education and Learning, 2(2), 36-43. https:// doi.org/10.5539/jel.v2n2p36

Bako Umar, B., Eric Krauss, S., Abu Samah, A., \& Abdul Hamid, J. (2017). Youth Voice in Nigerian School-based Management Committees. International Journal of Education and Literacy Studies, 5(1), 86. https:/ / doi.org/10.7575/aiac.ijels.v.5n.1p.86

Bandur, A. (2012). School-based management developments: Challenges and impacts. Journal of Educational Administration, 50(6), 845-873. https://doi.org/10.1108/09578231211264711

Cheng, Y. C. (1993). The theory and characteristics of school-based management. International Journal of Educational Management, 6-17. https://doi.org/10.1108/09513549310046659

Elmelegy, R. I. (2015). School-based management: An approach to decision-making quality in Egyptian general secondary schools. School Leadership and Management, 35(1), 79-96. https://doi.org/10.1080/13632434.2014.962499

Grinshtain, Y., \& Gibton, D. (2018). Responsibility, authority, and accountability in schoolbased and non-school-based management: Principals' coping strategies. Journal of Educational Administration, 56(1), 2-17. https:// doi.org/10.1108/JEA-01-2017-0005

Hasbullah. (2006). Otonomi Pendidikan: Kebijakan Otonomi Daerah dan Implikasinya terhadap Kebijakan Pendidikan. Raja Grafindo Persada.

Kwan, P., \& Li, B. Y. man. (2015). Empowerment or impediment? School governance in the school-based management era in Hong Kong. Asia Pacific Journal of Education, 35(3), 319-330. https://doi.org/10.1080/02188791.2015.1056592

Laurens Kaluge, L., \& Lilik Kustiani, L. (2017). School-Based Management in Indonesian Basic Education: Good Practices in the Past. May. https:/ / doi.org/10.2991/coema-17.2017.46

Lee, D. H. L., \& Chiu, C. S. (2017). "School banding": Principals' perspectives of teacher professional development in the school-based management context. Journal of Educational Administration, 55(6), 686-701. https:// doi.org/10.1108/JEA-02-2017-0018

Menteri Pendidikan Nasional. (2009). Peraturan Menteri Pendidikan Nasional Republik Indonesia Nomor 58 Tahun 2009 Tentang Standar Pendidikan Anak Usia Dini. In Menteri Pendidikan Nasional. Menteri Pendidikan Nasional.

Moradi, S., Beidokhti, A. A., \& Fathi, K. (2016). Comparative Comparison of Implementing School-Based Management in Developed Countries in the Historical Context: From Theory to Practice. International Education Studies, 9(9), 191. https://doi.org/10.5539/ies.v9n9p191

Mujiburrahman, Ridha, \& Mahmudin. (2018). Manajemen Berbasis Sekolah berorientasi pelayanan publik : teori dan implementasinya. In Yogyakarta: Zahir Publishing, Juli 2018 (Vol. 1, Issue 1). https:/ / doi.org/10.24256/jpmipa.v1i1.86

Mulyasa, E. (2017). Manajemen Berbasis Sekolah: Konsep, Strategi dan Implementasi. Remaja Rosdakarya. 
Muslihah, O. E. (2015). Understanding the Relationship between School-Based Management, Emotional Intelligence and Performance of Religious Upper Secondary School Principals in Banten Province. Higher Education Studies, 5(3), 11-23. https:// doi.org/10.5539/hes.v5n3p11

Ng, P. T., \& Chan, D. (2008). A comparative study of Singapore's school excellence model with Hong Kong's school-based management. International Journal of Educational Management, 22(6), 488-505. https:/ / doi.org/10.1108/09513540810895426

Nir, A. E. (2013). School-Based Management and the Centralisation Trap: An Evidence-Based $\begin{array}{llll}\text { Perspective. Curriculum } & \text { 29-45. }\end{array}$ https:// doi.org/10.7459/ct/27.2.03

Nurhasanah, \& Dwiyama, F. (2019). Pengembangan Lembaga PAUD melalui Implementasi Manajamen Berbasis Sekolah Nurhasanah 1 , Fajri Dwiyama 2. Adaara Jurnal Manajemen Pendidikan Islam, 8(1), 800-815.

Roza, D., Nurhafzah, \& Yaswinda. (2020). Urgensi Profesionalisme Guru Pendidikan Anak Usia Dini dalam Penyelenggaraan Perlindungan Anak. Jurnal Obsesi : Jurnal Pendidikan Anak Usia Dini, 4(1), 267-273. https://doi.org/10.31004/obsesi.v4i1.325

Sjamsir, H., Gunarto, B. H., Mulawarman, U., Kuaro, J., \& Kelua, G. (2017). Membangun Kemitraan Menuju Lembaga Mandiri. Manajemen San Supervisi Pendidikan, 1(2), 165170.

Sugiyono. (2017). Metode Penelitian Pendidikan: Pendekatan Kuantitatif, Kualitatif dan RED. Alfabeta.

Vally, G. V. S., \& Daud, K. (2015). The Implementation of School Based Management Policy: An Exploration. Procedia - Social and Behavioral Sciences, 172, 693-700. https:// doi.org/10.1016/j.sbspro.2015.01.421

Yunita, W., Utami, D., Jamaris, M., \& Meilanie, S. M. (2020). Evaluasi Program Pengelolaan Lembaga PAUD di Kabupaten Serang Abstrak. Jurnal Obsesi: Jurnal Pendidikan Anak Usia Dini, 4(1), 67-76. https:/ / doi.org/10.31004/obsesi.v4i1.259

Zengele, T. (2015). the Advent of School Based Management in the 21St Century. E-Bangi, 12(2). 